\title{
Role of global teleconnections and moisture sources in triggering extreme events in Indian Summer Monsoon realm
}

\author{
YADAV ANKIT ${ }^{1}$ ANOOP AMBILI $^{1}$
}

1ankit@iisermohali.ac.in

2anoop@iisermohali.ac.in

Indian summer monsoon is closely linked to meridional shifts of the Intertropical Convergence Zone (ITCZ), El NiñoSouthern Oscillation (ENSO) and Indian Ocean Dipole (IOD). The characteristics and mechanism explaining the association of mentioned teleconnections to monsoonal precipitation is still debatable. Here, we reconstruct a calibrated 2000-yr-long continuous record to have comprehensive picture of late Holocene climate variability over the North-Eastern Indian subcontinent (NEI). Our records, based on multi-proxy $\left(\delta^{13} \mathrm{C}, \delta^{15} \mathrm{~N}, n\right.$-alkane, grain size (D[4,3]- De Brouckere Mean Diameter)) approach have demonstrated an enhanced ISM precipitation from $1000 \mathrm{cal}$ yr BP contrasting to the Core Monsoon Zone (CMZ).

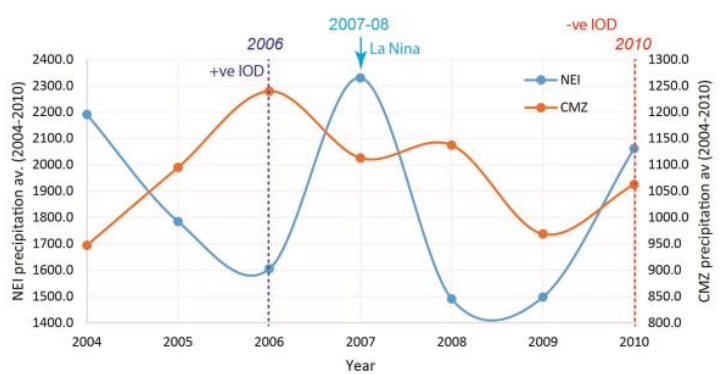

The proxies results are very well corroborated to the proxy record of upwelling intensity from Arabian Sea suggesting an increase in monsoon winds. Furthermore, the variation in Indian Summer Monsoon is very well characterised with centennial timescale active-break periods responding to slowly-evolving changes in ISM dynamics producing a quasi east-west precipitation dipole over Indian subcontinent. 